\title{
Prostate Kaposi Sarcoma
}

National Cancer Institute

\section{Source}

National Cancer Institute. Prostate Kaposi Sarcoma. NCI Thesaurus. Code C5523.

A Kaposi sarcoma arising from the prostate. 